\title{
Koch's Postulates to Metagenome and Next- Generation Sequencing, But what is Next?
}

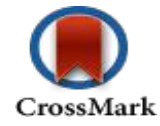

\author{
Santanu Chattopadhyay
}

Microbiome Research Facility, Rajiv Gandhi Centre for Biotechnology, Thiruvananthapuram, Kerala, India

*Corresponding author: Santanu Chattopadhyay, Ph. D, Microbiome Research Facility, Rajiv Gandhi Centre for Biotechnology, Thycaud Post, Poojappura, Thiruvananthapuram- 695 014, Kerala, India. Phone: +91- 471-2529400 | 2347975 | 2348753; Fax : +91-471-2348096; E-mail: santanu@rgcb.res.in

Citation: Chattopadhyay, S., et al. Koch's Postulates to Metagenome and Next-Generation Sequencing, But What is Next? (2015) J Gastrointest Disord Liver Func 2(1): 1-2.

"The pure culture is the foundation of all research on infectious disease"

Robert Koch received the Nobel Prize in Physiology or Medicine in the year 1905 for his discoveries in relation to tuberculosis, which at that time was one of the most important diseases and was responsible for numerous deaths. For Mycobacterium tuberculosis, Koch was able to show that the bacterium follow his postulates, which means that the pathogen can be found only in diseased animals and not in healthy animals, can be isolated in pure form from the diseased animals, has the potential to cause disease when introduced in healthy animals and can be re-isolated from the diseased animals ${ }^{[2]}$. Exactly 100 years after Koch's Nobel Prize, in 2005, Barry Marshall and Robin Warren received the Noble Prize in Physiology or Medicine for the identification and culture of the curved bacilli, Helicobacter pylori, the most important infectious etiologic agent for gastritis, duodenal and gastric ulcer as well as gastric adenocarcinoma ${ }^{[3]}$. To prove Koch's postulates Barry Marshall consumed H. pylori and he had massive gastritis, achlorhydria and vomiting before he took antibiotics for the eradication of the introduced H. pylori ${ }^{[4]}$. Later, when the animal models for $H$. pylori became available, the contributions of the bacterium and its virulence factors in developing peptic ulcer and gastric cancer have been firmly established ${ }^{[5,6]}$. Thus, for H. pylori, the second and the third postulates of Robert Koch has been demonstrated. Interestingly, however, it is well known that approximately $50 \%$ of the world population carry this bacterium in their stomach and only $10-20 \%$ of them develop the above mentioned gastric and duodenal disorders ${ }^{[7]}$. Why $\sim 80 \%$ of the $H$. pylori infected population does not become sick? In other words, why the very first postulate of Koch, which says that the infectious agent must be present only in diseased animals and not in healthy animals, is not valid for H. pylori?

H. pylori infection and clinical outcomes depend on several complicated and not fully understood factors. Prevalence of $H$. pylori infection and its virulence markers as well as the diseases vary with geography. Some of the virulence genes of $H$. pylo$r i$, like $\operatorname{cag} A$ and $v a c A$ have been linked with cancer and ulcer for some countries, but not for other countries ${ }^{[8]}$. Also, H. pylori is naturally competent, extremely efficient in horizontal gene transfer, causes long-term colonization and is believed to be co-evolved with human ${ }^{[9]}$. Therefore, the host genetic background should play a critical role in determining the disease outcome. Indeed, polymorphisms in several of the genes that encode cytokines like IL-1 $\beta$ and TNF $\alpha$ are connected with $H$. pylori related diseases ${ }^{[10]}$. But, is H. pylori the only pathogen that fails to show any direct manifestation of Koch's first postulate? Many viral infections, like hepatitis B virus or herpes virus, show no clinical manifestations for many individuals and the infections may remain benign for decades. But, let's take the most dramatic example of Vibrio cholerae, another microbe that was isolated by Robert Koch. Unlike H. pylori, it is fast growing, infections are acute and self-limiting. Moreover, this bacterium secretes an extremely potent toxin, the cholera toxin. Seven pandemics and numerous epidemics have been caused by the serotypes of $V$. cholerae that produce this toxin. But in the recent past, presence of Vibrio cholerae/mimicus infection has been shown in healthy children in Kolkata, India ${ }^{[11]}$. These children live in hygienic condition and therefore, infection with $V$. cholerae is not impossible. But why did they not become sick? Importantly, isolation of $V$. cholerae from healthy subjects was reported also in the past ${ }^{[2,12]}$. But quite fascinatingly, many 
of these healthy Indian children were also infected by different pathotypes of diarrheagenic Escherichia coli, Campylobacter coli / jejuni and rotavirus ${ }^{[11]}$. Apparently, we get infections from the environment and eventually the infections get cleared due to the self-limiting nature of some pathogens and also due to the host immunity, which varies from person to person. But there are more reasons than that. Recently, it has been shown that the presence of a particular bacterium, Ruminococcus obeum in human gut is involved in recovery from Vibrio cholerae infection by quorum sensing ${ }^{[13]}$. Therefore, interactions among microbes are one of the key factors in determining the disease status of the host. Also, one infection can help in developing immunity against other infections. It has been shown in murine model that the infection with latent gammaherpesvirus helps in developing immunity against Listeria monocytogenes infection through the upregulation of surface Major Histocompatibility Complex (MHC) class II in macrophages ${ }^{[14]}$. For H. pylori, unfortunately, distinct microbial interactions and their functions are not well documented, even though few groups tried to study microbial population in stomach ${ }^{[15,16]}$. Importantly, the negative association between $R$. obeum and $V$. cholerae was first picked up by metagenomic analysis and then confirmed by infection in mice ${ }^{[13]}$.

During the last decade, metagenomic analyses are not just limited to environmental samples like soil and seawater. Now, the next-generation sequencers are routinely used to understand microbiome, the genome of all microbes in and on our body metagenomically, without the need of culturing the microbe. Numerous studies have highlighted the importance of maintaining a healthy microbiome and have shown that the alteration of gut microbiome is also associated with many non-communicable diseases including many cancers, metabolic and neuronal disorders ${ }^{[17-20]}$. Thus, for a modern scientist, there is no choice but to appreciate the modern methods of analyzing microbes without actually culturing them. Importantly, for most of the several trillions of microbes that share our body space, we do not have proper culture methods. Also, analyses of the genetic materials by various methods were proven to be extremely valuable tool for the discovery of several viruses and can become even more useful in coming years ${ }^{[21-24]}$. Therefore, many modern scientists tend to ignore the famous quote by Robert Koch, which is mentioned in the beginning of this editorial. But we cannot forget the basics. The microorganisms that can be propagated can be studied using numerous tools of molecular biology, immunology and biochemistry. For instance, research on Hepatitis $\mathrm{C}$ virus has been benefited tremendously after its first successful culture in $2005^{[25,26]}$. Therefore, we, the present day scientists, must analyze microbiome and virome metagenomically, but should also develop newer methods to culture microbes that are difficult or even impossible to culture now. Future scientists deserve better tools for their research.

\section{References}

1. Koch, R. Zur Untersuchungen von pathogenen Organismen. Mittheilungen aus dem Kaiserlichen Gesundheitsamte (1881) 1: 1-48.

2. Fredricks, D.N., Relman, D.A. Sequence-based identification of microbial pathogens: a reconsideration of Koch's postulates. (1996) Clin Microbiol Rev 9(1): 18-33.

3. Marshall, B.J., Warren, J.R. Unidentified curved bacilli in the stomach of patients with gastritis and peptic ulceration. (1984) Lancet 1(8390): 1311-1315.
4. Marshall, B.J., Armstrong, J.A., McGechie, D.B., et al. Attempt to fulfil Koch's postulates for pyloric Campylobacter. (1985) Med J Aust 142(8): 436-439.

5. Hatakeyama, M. Anthropological and clinical implications for the structural diversity of the Helicobacter pylori CagA oncoprotein. (2011) Cancer Sci 102(1): 36-43.

6. Peek, R.M. Helicobacter pylori infection and disease: from humans to animal models. (2008) Dis Model Mech 1(1): 50-55.

7. Dorer, M.S., Talarico, S., Salama, N.R. Helicobacter pylori's unconventional role in health and disease. (2009) PLoS Pathog 5(10): e1000544.

8. Yamaoka, Y. Mechanisms of disease: Helicobacter pylori virulence factors. (2010) Nat Rev Gastroenterol Hepatol 7(11): 629-641.

9. Covacci, A., Telford, J.L., Del Giudice, G., et al. Helicobacter pylori virulence and genetic geography. (1999) Science 284(5418): 13281333

10. Datta De, D., Roychoudhury, S. To be or not to be: The host genetic factor and beyond in Helicobacter pylori mediated gastro-duodenal diseases. (2015) World J Gastroenterol 21(10): 2883-2895.

11. Nair, G.B., Ramamurthy, T., Sur, D., et al. Vibrio cholerae/mimicus in fecal microbiota of healthy children in a cholera endemic urban slum setting in Kolkata, India. (2012) Microbiol Immunol 56(11): 789-791.

12. Evans, A.S. Causation and disease: the Henle-Koch postulates revisited. (1976) Yale J Biol Med 49(2): 175-195.

13. Hsiao, A., Ahmed, A.M., Subramanian, S., et al. Members of the human gut microbiota involved in recovery from Vibrio cholerae infection. (2014) Nature 515(7527): 423-426.

14. Barton, E.S., White, D.W., Cathelyn, J.S., et al. Herpesvirus latency confers symbiotic protection from bacterial infection. (2007) Nature 447(7142): 326-329.

15. Bik, E.M., Eckburg, P.B., Gill, S.R., et al. Molecular analysis of the bacterial microbiota in the human stomach. (2006) Proc Natl Acad Sci USA 103(3): 732-737.

16. Dicksved, J., Lindberg, M., Rosenquist, M., et al. Molecular characterization of the stomach microbiota in patients with gastric cancer and in controls. (2009) J Med Microbiol 58(Pt 4): 509-516.

17. Clemente, J.C., Ursell, L.K., Parfrey, L.W., et al. The impact of the gut microbiota on human health: an integrative view. (2012) Cell 148(6): 1258-270.

18. Hill, J.M., Clement, C., Pogue, A.I., et al. Pathogenic microbes, the microbiome, and Alzheimer's disease (AD). (2014) Front Aging Neurosci 6: 127.

19. Parekh, P.J., Balart, L.A., Johnson, D.A. The Influence of the Gut Microbiome on Obesity, Metabolic Syndrome and Gastrointestinal Disease. (2015) Clin Transl Gastroenterol 6: e91.

20. Zitvogel, L., Galluzzi, L., Viaud, S., et al. Cancer and the gut microbiota: an unexpected link. (2015) Sci Transl Med 7(271): 271 ps1.

21. Feng H, Shuda M, Chang Y, et al. Clonal integration of a polyomavirus in human Merkel cell carcinoma. (2008) Science 319(5866): 1096-1100.

22. Chang, Y., Cesarman, E., Pessin, M.S., et al. Identification of herpesvirus-like DNA sequences in AIDS-associated Kaposi's sarcoma. (1994) Science 266(5192): 1865-1869.

23. Daly, G.M., Bexfield, N., Heaney, J., et al. A viral discovery methodology for clinical biopsy samples utilising massively parallel next generation sequencing. (2011) PLoS One 6(12): e28879.

24. Temmam, S., Monteil-Bouchard, S., Robert, C., et al. Host-Associated Metagenomics: A Guide to Generating Infectious RNA Viromes. (2015) PLoS One 10(10): e0139810.

25. Zhong, J., Gastaminza, P., Cheng, G., et al. Robust hepatitis C virus infection in vitro. (2005) Proc Natl Acad Sci USA 102(26): 9294-9299. 26. Lindenbach, B.D., Evans, M.J., Syder, A.J., et al. Complete replication of hepatitis C virus in cell culture. (2005) Science 309(5734): 623-626. 